\title{
建筑给排水设计中节能减排设计研究
}

杨 静

江苏省建筑工程集团有限公司，江苏南京 225009

\begin{abstract}
[摘要]近年来，在多方面利好因素的影响下，使得我国综合国力得到了显著的提升，从而为城市化建设工作的全面实施带来 了良好的机遇。在这种发展形势下，城市人口数量不断增加，从而为建筑工程项目提出了更高的要求。在整个建筑工程结构 中, 给排水工程是其中较为重要的一项基础工程, 这项工程整体水平和性能往往都与整个建筑工程项目综合性能和质量存在 密切的关联。在我国全面落实可持续发展的理念的影响下，在实施建筑给排水设计工作的时候，务必要充分结合各方面因素 加以综考虑, 有效的提升水资源的利用效率, 为城市建设工作全面实施加以保障。
\end{abstract}

[关键词]建筑给排水; 节能减排; 设计要点

DOI：10.33142/aem.v2i8.2796 中图分类号: TU82 文献标识码：A

\section{Research on Energy Saving and Emission Reduction Design in Building Water Supply and Drainage Design}

YANG Jing

\author{
Jiangsu Provincial Construction Group Co., Ltd., Nanjing, Jiangsu, 225009, China
}

\begin{abstract}
In recent years, under the influence of many favorable factors, China's comprehensive national strength has been significantly improved, which has brought good opportunities for the full implementation of urbanization. In this development situation, the number of urban population is increasing, which puts forward higher requirements for construction projects. In the whole construction engineering structure, water supply and drainage engineering is one of the more important foundation projects. The overall level and performance of this project are often closely related to the comprehensive performance and quality of the whole construction project. Under the influence of China's comprehensive implementation of the concept of sustainable development, in the implementation of building water supply and drainage design work, we must fully consider all aspects of factors, effectively improve the utilization efficiency of water resources, and ensure the comprehensive implementation of urban construction.
\end{abstract}

Keywords: building water supply and drainage; energy saving and emission reduction; design points

引言

在社会经济飞速发展的带动下, 人们生活水平的不断提升, 使得民众对环保工作越发的重视, 为了能够从根本上提 升建筑工程的环保性能, 那么最为重要的就是需要从各个细节入手将环保理念加以实践运用。鉴于此, 这篇文章主要针 对建筑给排水设计中节能减排设计展开全面深入的研究分析，希望能够对我国建筑工程行业的稳步健康发展有所帮助。

1 建筑给排水设计存在的问题

1.1 排水系统设计存在的问题

在整个建筑给排水系统之中, 各个管道之间的衔接问题与整个系统质量和稳定性存在密切的关联。给排水管道之 间的衔接效果往往会对管道密封性存在直接的直接的影响, 如果管道结构在连接的过程中发生任何的问题, 那么势必 会对整个管道系统的密封性造成严重的损害, 甚至会引发管道泄漏的情况, 最终会对周边环境造成污染。所以, 在针 对建筑给排水系统进行设计工作的时候, 务必要对管道之间的衔接加以综合考虑。排水管道自身质量与整个排水系统 的通畅性和稳定性密切相关, 高品质的排水管道能够切实的保障排水系统的使用效果, 提升整个排水管道系统的稳定 性, 还能够切实的规避管道泄漏的情况发生。一般来说, 排水管道系统都是被安设在地下的, 如果管道发生任何的破 损的情况, 那么必然会对管道的维保工作的有序开展造成诸多的制约, 所以在针对建筑排水系统进行设计工作的时候, 务必要严格的针对管道材料进行挑选, 从根本上对管道系统质量加以保障 ${ }^{[1]}$ 。

1.2 给水系统设计存在的问题

在城市化建设工作全面实施的影响下, 高层建筑以及超高层建筑的数量不断增加, 为了切实的满足民众对水资源的需求 量, 针对供水系统进行加压是最为有效的一种方法, 但是如果加压超出了既定的标准范围, 那么极易引发严重的不良后果。 现如今, 建筑给排水系统中出现频率较高的问题就是给水超压的问题。如果给水系统持续处在高压的情况下, 不但会导致给 谁稳定性的下降, 并且还会对给水系统中的各个基础设施造成一定的损害, 甚至会引发管道渗漏的情况发生。所以, 在针对 建筑给水系统进行设计工作的时候, 要充分结合各方面实际情况来设计压力参数, 从而规避发生给水超压的情况 ${ }^{[2]}$ 。 


\section{2 建筑给排水设计的研究意义}

近年来，我国社会经济水平得到了全面的提升，从而有效的推动了建筑工程行业的持续稳定发展。经过对大量的信息数据 进行综合分析发现, 在全国整体能耗中, 建筑工程行业能耗占比较大, 并且引发了严重的环境污染情况的发生。在当前我国全 面实施可持续发展理念的影响下, 人们对于节能环保工作给予了更多的关注, 从而使得各个领域环保意识不断提升, 环保节能 理念所具有的重要影响作用越发的凸显出来。将环保理念切实合理的引用到建筑给排水设计之中, 不但可以从根本节省建筑工 程运营成本, 并且还可以增强整个建筑工程的整体环保性能 ${ }^{[3]}$ 。在实际针对建筑给排水系统进行设计的时候, 因为基础施工技 术已经达到了较高的水平, 所以需要将施工的重点放在怎样节水和节能方面, 将节能环保理念加以切实的运用是未来建筑工程 领域发展的必然趋势。当下, 很多建筑给排水系统在节能环保方面存在诸多的问题, 从而会导致严重的水资源浪费的情况。给 排水设备整体质量和性能不达标，往往会引发系统渗漏的问题，从而也会对民众的正常生活造成不良影响。切实的将节能环保 理念加以实践运用，有效的提升水资源的利用效率，尽可能的避免对环境造成污染，是符合社会发展的实际需要的。

\section{3 给排水节能减排措施}

\section{1 对给排水设计过程进行优化}

要想从根本上对给排水设计的效果加以保障, 提升设计的整体水平, 那么需要在完成给排水系统的设计工作之后, 安排专 业人员针对设计结果进行综合分析，对于设计中所存在的问题要第一时间进行纠正，从而保证设计具有良好的可信性。在实施 建筑给排水设计工作的过程中, 务必要充分结合各方面情况加以综合考虑, 对于不同的需要要采用不同的设计方法, 并且设计 工作人员还应当具备良好的专业能力, 在充足的理论知识和实践经验的基础上, 能够对建筑给排水设计质量加以保证。在设计 过程中需要利用专业的工具和方法来对预留给排水管道位置进行准确的测量, 并且应当针对给排水管道材料的规格进行综合考虑 ${ }^{[4]}$ 。

\section{2 采取有效的节水措施}

在实际实施建筑给排水系统设计工作的时候，合理的运用信息技术能够起到提升建筑给排水设计质量的作用。设计工作人 员可以结合各方面实际情况, 针对需要的信息数据进行统一的收集、整理, 在工作秉承节能环保理念, 提升建筑给排水系统设 计的整体节水性能, 提升水资源的利用效率。切实的运用信息化的技术来针对所有信息进行统一的整理和分析, 并且运用电子 计算机技术来创设立体模型, 提升建筑工程整体结构的设计准确性。建筑给水工程设计工作人员务必要具备良好的节水意识, 在设计过程中，合理的设置水龙头等重点节水措施，能够合理的控制整体生产成本，增强建筑给排水设计的实用性 ${ }^{[5]}$ 。

\section{3 建筑给排水设计中的相互配合}

在实际开展建筑给排水工程设计工作的过程中, 设计单位务必要对各项工作进行合理的调配, 并且要做好各项工 作之间的调节, 提升建筑给排水设计的整体水平。在实际开展设计工作的时候, 给排水工程要结合建筑各方面实际情 况, 来设计排水管道的安设方向, 这样才能确保排水管道线路的合理性。给排水系统的设计需要与整个工程设计保证 良好的统一性, 并且要与其他系统设计工作人员进行沟通交流, 不但能够提升设计的整体效果, 并且还可以结合其他 系统设计来选择最佳的设计方案, 提升给排水系统的综合性能, 保证建筑工程整体美观性。

\section{4 建筑排水系统的设计要点}

(1) 排水系统通常都是用作排放民众生活中所产生的各种污水。污水处理是所有建筑工程都需要解决的一项重要 问题, 在实施建筑工程设计工作的时候, 不但需要对管道处理污水的能力加以综合考虑, 并且还需要研究在确保系统 能够正常运行的基础上，尽可能的提升系统的环保节能性能。

(2) 在建设给排水的工程中, 要引入节能的理念, 运用科学技术、设备和材料, 尤其是已经通过实验有作用的材 料, 像铝塑复合管, 不仅抗腐蚀, 连接处也很好处理, 这样就能够避免管路的渗漏问题, 另外合理设计的同时, 也要 跟施工单位进行相互的配合, 对于有些不符合设计条件的地形位置, 可以根据施工经验来进行合理的修改, 这样才能 避免资源的浪费, 更好地保证建筑给排水工程的建设。

\section{4 结语}

总的来说, 建筑给排水设计不但与民众的生活密切相关, 并且也会对建筑工程施工单位未来发展造成一定的影响, 为了切实的提升资源利用效率, 推动整个社会和谐稳定发展, 那么最为重要的就是要将环保节能理念加以切实的运用, 并且与建筑给排水设计融合在一起，为建筑工程行业的持续稳定发展创造良好的基础。

\section{[参考文献]}

[1]赵兰萍,魏征. 建筑给排水设计中节能减排设计分析 [J]. 科技创新导报, 2019, 16 (31): 157-159.

[2] 马鹤. 建筑给排水设计中节能减排设计分析 [J]. 工程技术研究, 2019,4(15): 159-161.

[3]贾丽. 建筑给排水设计中节能减排设计探究 [J]. 山西建筑, 2019, 45 (10) : 180-181.

[4] 张赛燕. 建筑给排水设计中节能减排设计分析 [J]. 工程技术研究, 2017 (04) : 225-237.

[5]魏敏. 试论建筑给排水设计中节能减排设计 [J]. 建材与装饰, 2016 (40): 75-76.

作者简介: 杨静 (1989.3-), 女, 江苏扬州人, 汉族, 大学学历, 江苏省建筑工程集团有限公司, 从事给排水工程设计工作。 